\title{
Cinchona-Derived Picolinamides: Effective Organocatalysts for Stereoselective Imine Hydrosilylation
}

\author{
Pedro C. Barrulas, ${ }^{[a]}$ Andrea Genoni, ${ }^{[b]}$ Maurizio Benaglia, ${ }^{*[b, c]}$ and Anthony J. Burke*[a]
}

Keywords: Alkaloids / Imines / Reduction / Organocatalysis / Lewis bases

Picolinamide-cinchona organocatalysts for the successful enantioselective reduction of ketomines were developed. For the first time, a new type of chiral Lewis base, a cationic species, is reported to efficiently organocatalyze the addition of trichlorosilane to imines. Excellent yields with good to high enantioselectivities (up to $91 \%$ ) were obtained in the reduction of differently substituted substrates. Noteworthy, remarkably high turnover frequencies for the hydrosilylation of imines were observed; the catalyst of choice proved to be active even at a loading of only $1 \mathrm{~mol}-\%$. The loading was further reduced to $0.5 \mathrm{~mol}-\%$, and for very short reaction times (15 min) very impressive asymmetric catalyst efficiency speed values were reached.

\section{Introduction}

Organocatalysis ${ }^{[1]}$ has already made significant contributions to the production and discovery of new pharmaceuticals, agrochemicals, and other high added-value compounds. ${ }^{[2]}$ Metal-free catalysts based on the cinchona skeleton are well known and have been employed for a diversity of reactions. ${ }^{[3]}$ On the other hand, Lewis base based organocatalysts have been exploited with success in the stereoselective trichlorosilane-mediated reduction of $N$-substituted ketoimines ${ }^{[4]}$ and in the asymmetric Biginelli reaction. ${ }^{[5]}$ The hydrosilylation reaction is a widely employed method for accessing enantiomerically enriched amines, ${ }^{[6]}$ and it is extremely useful from an industrial perspective, as it affords chiral products by using typically very cheap reducing agents. ${ }^{[7]}$ Several groups have used the organocatalytic strategy for the hydrosilylation of ketoimines. ${ }^{[8]}$ Among the most successful Lewis bases used to activate $\mathrm{HSiCl}_{3}$ are the picolinamides, simply synthesized by connecting picolinic acid to a chiral carbon skeleton. ${ }^{[9]}$

We now wish to report our preliminary results on the application of novel picolinamide-cinchona organocatalysts for the successful highly enantioselective trichlorosilanemediated reduction of ketomines to chiral amines; more-

[a] Department of Chemistry and Chemistry Center of Évora, University of Évora,

Rua Romão Ramalho 59, 7000 Évora, Portugal

E-mail: ajb@dquim.uevora.pt

[b] Dipartimento di Chimica, Università degli Studi di Milano,

Via Golgi 19, 20133 Milano, Italy

E-mail: maurizio.benaglia@unimi.it

http://www.dipchi.unimi.it

http://www.unimi.it

[c] Istituto di Scienze e Tecnologie Molecolari, ISTM-CNR, Via Golgi 19, 20133 Milano, Italy

Supporting information for this article is available on the WWW under http://dx.doi.org/10.1002/ejoc.201403180. over, as far as we are aware, we have achieved the highest turnover frequency for the hydrosilylation of imines to date. ${ }^{[10]}$

\section{Results and Discussion}

Two types of picolinamide-cinchona catalysts were studied: neutral derivatives and pyridine- $N$-methylated compounds (methylated pyridinium salts $\mathbf{4}$ and 5, Figure 1). Our rationale was that in the former case the picolinamide unit would coordinate to the silicon atom with the carboxyamide group and the pyridine nitrogen atom in an octahedral hexacoordinate complex, as usual for this class of catalysts; in the latter case, different $\mathrm{HSiCl}_{3}$ activation modes may be envisaged: hexacoordination of the $\mathrm{Si}$ atom with the $\mathrm{CO}$ amide group and the quinuclidine $\mathrm{N}$ atom or complexation of trichlorosilane with the only amide oxygen atom to generate a pentacoordinate silane are both possible.

Organocatalysts 1-7 were prepared by using amide coupling and methylation (in the case of $\mathbf{4}$ and 5) procedures (Figure 1, for further details see the Supporting Information). ${ }^{[10]}$ All the catalysts were screened in a preliminarily test reaction: the hydrosilylation of the $N$-phenyl imine of acetophenone by using trichlorosilane (3 equiv.) and the catalyst $(10 \mathrm{~mol}-\%)$ in dry $\mathrm{CH}_{2} \mathrm{Cl}_{2}$ (Scheme $1 ; \mathrm{R}^{1}=\mathrm{H}, \mathrm{R}^{2}$ $\left.=\mathrm{Ph}, \mathrm{R}^{3}=\mathrm{Me}\right){ }^{[11]}$

In all cases, excellent yields and high enantioselectivities ranging from 77 to $90 \%$ ee were obtained (Table 1). Whereas epi-quinine derivatives $\mathbf{2}$ and $\mathbf{3}$ catalyzed the reaction generally with $80 \%$ ee, epi-quinidine derivatives $\mathbf{6}$ and 7 were more efficient in terms of both chemical and stereochemical efficiency; they afforded the chiral amine (with the opposite absolute configuration) in up to $90 \%$ ee. Lowering the reaction temperature resulted in only a marginal 

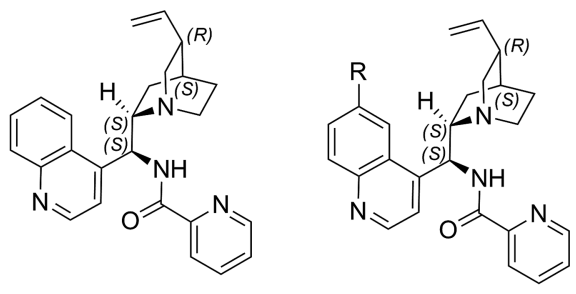

1

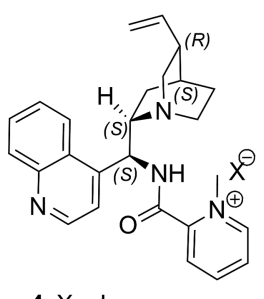

4: $X=1$ 5: $\mathrm{X}=\mathrm{BF}_{4}$

2: $\mathrm{R}=\mathrm{OMe}$

3: $\mathrm{R}=\mathrm{OH}$

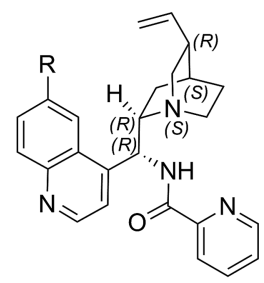

6: $\mathrm{R}=\mathrm{OMe}$

7: $\mathrm{R}=\mathrm{OH}$

Figure 1. Cinchona-pyridinecarboxyamide catalysts studied in this work.

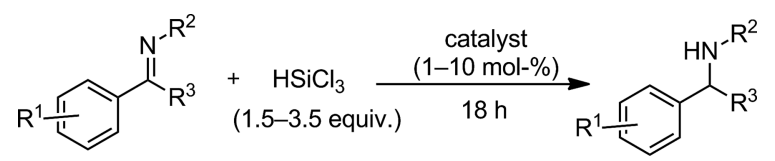

Scheme 1. Enantioselective organocatalytic reduction of ketoimines.

increase in the enantioselectivity. Noteworthy, epi-quininederived methylated pyridinium salts $\mathbf{4}$ and $\mathbf{5}$ promoted the formation of the $(S)$ enantiomer, as did corresponding neutral compound 1, with higher enantioselectivity, up to $90 \%$ $e e$ in the case of tetrafluoroborate salt 5 (Table 1, Entry 5).

Table 1. Screening results with catalysts $\mathbf{1}-\mathbf{7}$ in the hydrosilylation of the $\mathrm{N}$-phenyl imine of acetophenone.

\begin{tabular}{ccccc}
\hline Entry & Catalyst & $T\left[{ }^{\circ} \mathrm{C}\right]$ & Yield $^{[\mathrm{a}]}[\%]$ & $e e^{[\mathrm{b}]}[\%]$ \\
\hline 1 & $\mathbf{1}$ & 0 & 97 & $80(S)$ \\
2 & $\mathbf{2}$ & 0 & 91 & $77(S)$ \\
3 & $\mathbf{3}$ & 0 & 83 & $81(S)$ \\
4 & $\mathbf{4}$ & 0 & 77 & $79(S)$ \\
5 & $\mathbf{5}$ & 0 & 75 & $90(S)$ \\
6 & $\mathbf{6}$ & 0 & 98 & $81(R)$ \\
7 & 7 & 0 & 99 & $90(R)$ \\
8 & $\mathbf{6}$ & -20 & 51 & $83(R)$ \\
9 & $\mathbf{6}$ & -40 & 23 & $84(R)$ \\
\hline
\end{tabular}

[a] Yield of isolated product. [b] Determined by HPLC on a chiral stationary phase.

The catalytic behavior of neutral picolinamides $\mathbf{1 ,} \mathbf{6}$, and 7 in the reduction of different substrates was then briefly investigated (Scheme 1, Table 2). epi-Quinidine-based catalyst 7 featuring a hydroxy group on the quinoline ring proved to be constantly the best performer; it often afforded the corresponding chiral amines in quantitative yields with $90 \%$ ee.

Table 2. Reduction of ketoimines promoted by neutral chiral picolinamides.

\begin{tabular}{cccccc}
\hline Entry & $\mathrm{R}^{1} / \mathrm{R}^{2} / \mathrm{R}^{3[a]}$ & Catalyst & $\begin{array}{c}T \\
{\left[{ }^{\circ} \mathrm{C}\right]}\end{array}$ & $\begin{array}{c}\text { Yield } \\
{[\%]}\end{array}$ & $\begin{array}{c}e e \\
{[\%]}\end{array}$ \\
\hline 1 & $\mathrm{H} / \mathrm{Ph} / \mathrm{Et}$ & $\mathbf{1}$ & 25 & 77 & $81(S)$ \\
2 & $\mathrm{H} / \mathrm{Ph} / \mathrm{Me}$ & $\mathbf{1}$ & 0 & 97 & $80(S)$ \\
3 & $\mathrm{H} / \mathrm{Ph} / \mathrm{Me}$ & $\mathbf{6}$ & 0 & 93 & $81(R)$ \\
4 & $\mathrm{H} / \mathrm{Ph} / \mathrm{Me}$ & $\mathbf{7}$ & 0 & 99 & $90(R)$ \\
5 & $\mathrm{H} / \mathrm{PMP} / \mathrm{Me}$ & $\mathbf{7}$ & 0 & 97 & $90(R)$ \\
6 & 4-Cl/PMP/Me & 7 & 0 & 99 & $91(R)$ \\
7 & 4-Br/PMP/Me & 7 & 0 & 98 & $88(R)$ \\
8 & $3-\mathrm{Br} / \mathrm{PMP} / \mathrm{Me}$ & $\mathbf{7}$ & 0 & 77 & $89(R)$ \\
9 & $\mathrm{H} / \mathrm{PMP} / \mathrm{CO}_{2} \mathrm{Me}$ & $\mathbf{7}$ & 0 & 93 & $80(S)$ \\
10 & $\mathrm{H} / \mathrm{PMP} / \mathrm{CH}_{2} \mathrm{CO}_{2} \mathrm{Me}$ & $\mathbf{6}$ & 0 & 87 & $83(R)$ \\
11 & $\mathrm{H} / \mathrm{PMP} / \mathrm{CH}_{2} \mathrm{CO}_{2} \mathrm{Me}$ & $\mathbf{7}$ & 0 & 99 & $90(R)$ \\
\hline
\end{tabular}

[a] PMP $=p$-methoxyphenyl.

We also looked at imino esters: whereas $\alpha$-imino derivatives were reduced with decent enantioselectivity (Table 2, Entry $9 ; 93 \%$ yield with $80 \% e e$ ), $\beta$-imino esters were converted into $\beta$-amino esters in up to $99 \%$ yield with $90 \%$ ee (Table 2, Entries 10 and 11).

The activity of methylated, cationic catalysts was also investigated (Table 3). By using cationic species $\mathbf{4}$ and $\mathbf{5}$, derived from epi-cinchonidine, in the reduction of the $\mathrm{N}$ phenyl imine of propiophenone, the corresponding $(S)$ chiral amine was obtained as the major enantiomer; this indicated that the mechanism for the hydrosilylation of imines was equivalent to that operating with neutral picolinamides 1-3. The product was isolated in up to $84 \%$ ee at room temperature (Table 3, Entry 3).

Table 3. Hydrosilylation of ketoimines promoted by cationic picolinamide $\mathbf{5}$.

\begin{tabular}{|c|c|c|c|c|}
\hline Entry & $\mathrm{R}^{1 /} / \mathrm{R}^{2} / \mathrm{R}^{3[\mathrm{a}]}$ & $\begin{array}{c}T \\
{\left[{ }^{\circ} \mathrm{C}\right]}\end{array}$ & $\begin{array}{c}\text { Yield } \\
{[\%]}\end{array}$ & $\begin{array}{c}e e \\
{[\%]}\end{array}$ \\
\hline 1 & $\mathrm{H} / \mathrm{Ph} / \mathrm{Et}$ & 0 & 80 & $80(\mathrm{~S})$ \\
\hline 2 & $\mathrm{H} / \mathrm{Ph} / \mathrm{Et}$ & -20 & 79 & $80(S)$ \\
\hline 3 & $\mathrm{H} / \mathrm{Ph} / \mathrm{Et}$ & 25 & 86 & $84(S)$ \\
\hline $4^{[\mathrm{b}]}$ & $\mathrm{H} / \mathrm{Ph} / \mathrm{Et}$ & 25 & 47 & $65(S)$ \\
\hline 5 & $4-\mathrm{NO}_{2} / \mathrm{Ph} / \mathrm{Me}$ & 25 & 68 & $83(S)$ \\
\hline 6 & $4-\mathrm{MeO} / \mathrm{Ph} / \mathrm{Me}$ & 25 & 58 & $84(S)$ \\
\hline 7 & $4-\mathrm{MeO} / 4-\mathrm{BrC}_{6} \mathrm{H}_{4} / \mathrm{Me}$ & 25 & 10 & $69(S)$ \\
\hline 8 & $4-\mathrm{NO}_{2} / 3-\mathrm{BrC}_{6} \mathrm{H}_{4} / \mathrm{Me}$ & 25 & 75 & $76^{[\mathrm{c}]}$ \\
\hline 9 & $4-\mathrm{MeO} / 3-\mathrm{BrC}_{6} \mathrm{H}_{4} / \mathrm{Me}$ & 25 & 20 & $69^{[c]}$ \\
\hline 10 & $\mathrm{H} / \mathrm{Ts} / \mathrm{Et}$ & 25 & 73 & $73(S)$ \\
\hline 11 & $\mathrm{H} / \mathrm{PMP} / \mathrm{Me}$ & 0 & 71 & $89(S)$ \\
\hline 12 & $\mathrm{Cl} / \mathrm{PMP} / \mathrm{Me}$ & 0 & 85 & $83(S)$ \\
\hline 13 & $\mathrm{H} / \mathrm{PMP} / \mathrm{CO}_{2} \mathrm{Me}$ & 0 & 93 & $81(R)$ \\
\hline 14 & $\mathrm{H} / \mathrm{Ph} / \mathrm{CH}_{2} \mathrm{CO}_{2} \mathrm{Et}$ & 25 & 72 & $70^{[\mathrm{cc}]}$ \\
\hline 15 & $\mathrm{Br} / \mathrm{PMP} / \mathrm{CH}_{2} \mathrm{CO}_{2} \mathrm{Me}$ & 0 & $>99$ & $85(S)$ \\
\hline
\end{tabular}

[a] Ts $=p$-tolylsulfonyl. [b] Reaction was run in chloroform. [c] Major enantiomer configuration unknown.

The catalyst promoted the reaction with good chemical and stereochemical efficiency for a wide range of aryl ketoimines. Interestingly, a good level of enantioselectivity was maintained in the reduction of $N$-tosyl imines (Table 3, Entry 10), whereas higher $e e$ values were obtained with $N$-p methoxyphenyl-substituted ketoimines (Table 3, Entries 1113 and 15). 
Having thus determined the scope of catalyst $\mathbf{5}$ in the hydrosilylation reaction, we studied various loadings of this novel organocatalyst and looked at the turnover frequency (TOF), with a view to its industrial application. The results were very encouraging (Table 4): the loading of the catalyst was reduced to $1 \mathrm{~mol}-\%$, but the product was still obtained in $86 \%$ yield with $80 \%$ ee after a reaction time of $18 \mathrm{~h}$ (Table 4, Entry 4). Upon reducing the quantity of trichlorosilane to 1.5 equiv., the highest TOF of $31.0 \mathrm{~h}^{-1}$ (at a loading of 10 mol- $\%$ catalyst) was reached with a remarkable $87 \%$ ee. Noteworthy, these results favorably compare with the best results so far obtained with organocatalysts.

Table 4. Catalyst loading optimization studies of $\mathbf{5}$ in the hydrosilylation of the $N$-phenyl imine of propiophenone.

\begin{tabular}{cccccc}
\hline Entry & $\begin{array}{c}\mathbf{5} \\
{[\mathrm{mol}-\%]}\end{array}$ & $\begin{array}{c}\text { Yield }^{[\mathrm{a}]} \\
{[\%]}\end{array}$ & $\begin{array}{c}e e^{[\mathrm{b}]} \\
{[\%]}\end{array}$ & $\begin{array}{c}\text { TOF } \\
{\left[\mathrm{h}^{-1}\right]}\end{array}$ & $\begin{array}{c}\mathrm{ACES}^{[12]} \\
{\left[\mathrm{h}^{-1}\right]}\end{array}$ \\
\hline $1^{[\mathrm{c}]}$ & 20 & 85 & 85 & 0.24 & 0.08 \\
$2^{[\mathrm{c}]}$ & 10 & 86 & 84 & 0.48 & 0.17 \\
$3^{[\mathrm{c}]}$ & 5 & 88 & 82 & 0.98 & 0.34 \\
$4^{[\mathrm{c}]}$ & 1 & 86 & 80 & 4.78 & 1.61 \\
$5^{[\mathrm{c}]}$ & 0.5 & 80 & 72 & 8.67 & 2.64 \\
$6^{[\mathrm{d}]}$ & 10 & $81^{[\mathrm{e}]}$ & 90 & 8.1 & 3.08 \\
$7^{[\mathrm{d}]}$ & 5 & $67^{[\mathrm{e}]}$ & 88 & 13.4 & 4.98 \\
$8^{[\mathrm{d}]}$ & 10 & $77^{[\mathrm{f}]}$ & 88 & 15.4 & 5.72 \\
$9^{[\mathrm{d}]}$ & 10 & $55^{[\mathrm{g}]}$ & 87 & 31.0 & 8.03 \\
\hline
\end{tabular}

[a] Yield of isolated product. [b] Determined by HPLC on a chiral stationary phase. [c] Reaction time: $18 \mathrm{~h}$. [d] $\mathrm{HSiCl}_{3}$ (1.5 equiv.) was added. [e] Reaction time: 1 h. [f] Reaction time: 30 min. [g] Reaction time: $15 \mathrm{~min}$.

We also evaluated the asymmetric catalyst efficiency speed (ACES) on the basis of the asymmetric catalyst efficiency equation that was originally developed by ElFayyoumy et al. in 2009. ${ }^{[12]}$ This formula allows one to unambiguously compare the overall efficiency and briskness of any asymmetric catalytic process; the central dogma is that an asymmetric catalyst may be considered more efficient if fewer atoms are utilized to give a product with a specific ee value. The best result was obtained at a catalyst loading of $10 \mathrm{~mol}-\%$ with 1.5 equiv. of silane over $15 \mathrm{~min}$ $\left(8.03 \mathrm{~h}^{-1}\right.$; Table 4 , Entry 9$)$.

Overall, by using the ACES formula, this represents an excellent performance in terms of catalytic efficiency for the imine hydrosilylation reaction. For instance, in the case of this reaction the best ACES values were between 0.1 and $0.3 \mathrm{~h}^{-1}$. To date, only the imidazole-based catalyst reported by Jones's group in 2009 favorably compares with catalyst 5. ${ }^{[4 b, 13]}$ For the sake of comparison, in the case of the pioneering Hajos-Parrish-Eder-Sauer-Wiechert reaction ${ }^{[1]}$ with L-proline, the best ACES of $2.31 \mathrm{~h}^{-1}$ was obtained.

\section{Conclusions}

We reported a group of picolinamide-cinchona derivatives, including for the first time a chiral cationic picolinamide, that give excellent results in the hydrosilylation of ketoimines. Our studies revealed that we could reduce the loading of the catalyst down to $0.5 \mathrm{~mol}-\%$ and still obtain satisfactory results and very impressive ACES values. The newly developed multifunctional chiral Lewis bases represent an easy entry in an unexplored class of catalysts for stereoselective reductions that are characterized by multiple possible modes of action. We are currently investigating the mechanism of these catalysts, looking at their application in the synthesis of biologically active targets, and optimizing their immobilization to solid supports.

\section{Experimental Section}

General Remarks: Cinchonidine and all other reagents and solvents used in this work were purchased from Sigma-Aldrich, Fluka, or Acros Organics and were used as received. The imine substrates were prepared by using known methods. ${ }^{[14,15]}$ All details on the synthesis of the catalysts, analyses of the products, and characterization data are reported in the Supporting Information.

General Procedure for the Catalytic Asymmetric Hydrosilylation with Catalysts 1-7: The ketoimine $(0.33 \mathrm{mmol})$ and the organocatalyst $(0.1-20 \mathrm{~mol}-\%)$ were dissolved in dry $\mathrm{CH}_{2} \mathrm{Cl}_{2}(1 \mathrm{~mL})$. The mixture was then cooled in an ice bath; after $15 \mathrm{~min}, \mathrm{HSiCl}_{3}(1.5-$ 3 equiv.) was added dropwise. Once the addition was complete, the mixture was stirred at room temperature for $15 \mathrm{~min}$ to $18 \mathrm{~h}$. The reaction was quenched by the addition of a saturated solution of $\mathrm{NaHCO}_{3}(2 \mathrm{~mL})$. The organic phase was extracted with $\mathrm{CH}_{2} \mathrm{Cl}_{2}$ $(3 \times 10 \mathrm{~mL})$, dried with anhydrous $\mathrm{MgSO}_{4}$, filtered, and concentrated in vacuo. The resulting residue was purified by column chromatography with silica gel by using literature conditions. The enantiomeric excess was determined by using HPLC with chiral columns (for further details see the Supporting Information).

Supporting Information (see footnote on the first page of this article): Synthesis and characterization of the catalysts, synthesis of the imine, enantioselective reduction procedures, NMR and mass spectra, and HPLC traces of the organocatalytic reductions.

\section{Acknowledgments}

P. C. B. is grateful to the Fundação para a Ciência e a Tecnologia (FCT)for the award of a Ph.D. grant (SFRH/BD/61913/2009). This work was conducted by using finances from the FCT through strategic project PEst-OE/QUI/UI0619/2011. We acknowledge LabRMN at FCT-UNL for the acquisition of the NMR spectra; the NMR spectrometers are part of the National NMR Facility supported by the Fundação para a Ciência e a Tecnologia (RECI/ BBB-BQB/0230/2012). The staff at the MS laboratory at CACTI, University of Vigo, is acknowledged for the MS analyses. We thank Dr. Olivia Furtado Burke, Laboratório Nacional de Energia e Geologia (LNEG), Lisbon, for performing some of the optical rotation measurements. Chiratecnics Lda (www.chiratecnecnics.com) is acknowledged for its interest in this project and its valuable support. M. B. thanks European Cooperation in Science and Technology (COST) action CM9505 "ORCA" Organocatalysis. A. G. acknowledges the Università degli Studi di Milano for a Ph.D. fellowship.

[1] a) B. List, R. A. Lerner, C. F. Barbas III, J. Am. Chem. Soc. 2000, 122, 2395-2396; b) K. A. Ahrendt, C. J. Borths, D. W. C. MacMillan, J. Am. Chem. Soc. 2000, 122, 4243-4244.

[2] For key reviews/papers, see: a) J. Alemán, S. Cabrera, Chem. Soc. Rev. 2013, 42, 774-93; b) M. J. Gaunt, C. C. C. Johansson, A. McNally, N. T. Vo, Drug Discovery Today 2007, 12, 8-27; c) T. A. Davis, J. N. Johnson, Chem. Sci. 2011, 2, 1076-1079; d) 
G. Coulthard, W. Erb, V. K. Aggarwal, Nature 2012, 489, 27881.

[3] a) C. E. Song, Cinchona Alkaloids in Synthesis and Catalysis: Ligands, Immobilization and Organocatalysis, Wiley-VCH, Weinheim, 2009; b) Y. Xi, X. Shi, Chem. Commun. 2013, 49, 8583-8585; see also: P. C. Barrulas, M. Benaglia, A. J. Burke, Tetrahedron: Asymmetry 2014, 25, 923-935.

[4] Reviews: a) S. Guizzetti, M. Benaglia, Eur. J. Org. Chem. 2010, 5529-5541; b) S. Jones, C. J. A. Warner, Org. Biomol. Chem. 2012, 10, 2189-2200.

[5] D. Z. Xu, H. Li, Y. M. Wang, Tetrahedron 2012, 68, 7867-72.

[6] S. K. Ritter, Chem. Eng. News 2013, 91, 34. For reviews on the metal-catalyzed hydrogenation of imines and heteroaromatic systems, see: N. Fleury-Brégeot, V. de le Fuente, S. Castillón, C. Claver, ChemCatChem 2010, 2, 1346; Y.-G. Zhou, Acc. Chem. Res. 2007, 40, 1357-1371. See also: F. Glorius, Org. Biomol. Chem. 2005, 3, 4171-4175. For a review on organocatalyzed enantioselective reductions, see: M. Benaglia, A. Genoni, M. Bonsignore, "Enantioselective Organocatalytic Reductions" in Stereoselective Organocatalysis: From $\mathrm{C}-\mathrm{C}$ to $\mathrm{C}-$ Heteroatom Bond Formation (Ed.: R. Rios Torres), Wiley, Hoboken, NJ, 2012.

[7] T. C. Nugent, M. El-Shazly, Adv. Synth. Catal. 2010, 352, 753819; A. K. Ghose, V. N. Viswanadhan, J. J. Wendoloski, J. Comb. Chem. 1999, 1, 55-68.

[8] Selected, representative references for non-picolinamide-based catalysts: a) A. V. Malkov, A. Mariani, K. N. MacDougal, P. Kočovský, Org. Lett. 2004, 6, 2253-2256; b) A. V. Malkov, M. Figlus, S. Stončius, P. Kočovský, J. Org. Chem. 2009, 74, 58395849; c) A. V. Malkov, A. J. P. S. Liddon, P. Ramírez-López, L. Bendová, D. Haigh, P. Kočovský, Angew. Chem. Int. Ed. 2006, 45, 1432-1435; Angew. Chem. 2006, 118, 1460-1463; d) D. Pei, Z. Wang, S. Wei, Y. Zhang, J. Sun, Org. Lett. 2006, 8, 59135915; e) D. Pei, Y. Zhang, S. Wei, M. Wang, J. Sun, Adv. Synth. Catal. 2008, 350, 619-623; f) X. Wu, Y. Li, C. Wang, L. Zhou, X. Lu, J. Sun, Chem. Eur. J. 2011, 17, 2846-2848; g) M. Bonsignore, M. Benaglia, R. Annunziata, G. Celentano, Synlett 2011, 8, 1085-1088; h) Y.-C. Xiao, C. Wang, Y. Yao, J. Sun, Y.-C. Chen, Angew. Chem. Int. Ed. 2011, 50, 10661-10664; Angew. Chem. 2011, 123, 10849-10852; i) S. Jones, X. Li, Org. Biomol.
Chem. 2011, 9, 7860-7866; j) M. Bonsignore, M. Benaglia, L. Raimondi, M. Orlandi, G. Celentano, Beilstein J. Org. Chem. 2013, 9, 633-640; k) X. Liu, C. Wang, Y. Yan, Y. Wang, J. Sun, J. Org. Chem. 2013, 78, 6276-6280.

[9] Selected picolinamide catalysts: a) O. Onomura, Y. Kouchi, F. Iwasaki, Y. Matsumura, Tetrahedron Lett. 2006, 47, 3751-3754; b) H. Zheng, J. Deng, W. Li, X. Zhang, Tetrahedron Lett. 2007, 48, 7934-7937; c) S. Guizzetti, M. Benaglia, R. Annunziata, F. Cozzi, Tetrahedron 2009, 65, 6354-6363; d) S. Guizzetti, M. Benaglia, S. Rossi, Org. Lett. 2009, 11, 2928-2931; e) S. Guizzetti, M. Benaglia, G. Celentano, Eur. J. Org. Chem. 2009, 3683-3687; f) Y. Jiang, X. Chen, Y. Zheng, Z. Xue, C. Shu, W. Yuan, X. Zhang, Angew. Chem. Int. Ed. 2011, 50, 7304-7307; Angew. Chem. 2011, 123, 7442-7445; g) X. Chen, Y. Zheng, C. Shu, W. Yuan, B. Liu, X. Zhang, J. Org. Chem. 2011, 76, 91099115; h) Y. Jiang, X. Chen, X. Hu, C. Shu, Y. Zhang, Y. Zheng, C. Lian, W. Yuan, X. Zhang, Adv. Synth. Catal. 2013, 355, 1931-1936.

[10] a) P. C. Barrulas, A. J. Burke, Novel Picolinamide-Cinchona Organocatalysts and derivatives, PCT/IB2014/065128; b) P. C. Barrulas, Ph.D. Dissertation, University of Evora, 2014.

[11] For very recent contributions in the field, see also: a) A. Genoni, M. Benaglia, E. Massolo, S. Rossi, Chem. Commun. 2013, 49, 8365-8367; b) Z. Y. Wang, C. Wang, L. Zhou, J. Sun, Org. Biomol. Chem. 2013, 11, 787-97; c) D. Enders, A. Rembiak, M. Seppelt, Tetrahedron Lett. 2013, 54, 470-473.

[12] S. El-Fayyoumy, M. H. Todd, C. Richards, Beilstein J. Org. Chem. 2009, 5, 67-72.

[13] a) F. M. Gautier, S. Jones, S. J. Martin, Org. Biomol. Chem. 2009, 7, 229-231; b) F. M. Gautier, S. Jones, X. Li, S. J. Martin, Org. Biomol. Chem. 2011, 9, 7860-7868.

[14] a) J. S. M. Samec, J. Bäckvall, Chem. Eur. J. 2002, 8, 2955-61; b) S. H. Kwak, S. A. Lee, K. I. Lee, Tetrahedron: Asymmetry 2010, 21, 800-804; c) Y.-Q. Wang, S.-M. Lu, Y.-G. Zhou, J. Org. Chem. 2007, 72, 3729-34; d) P. Wu, Z. Wang, M. Cheng, L. Zhou, J. Sun, Tetrahedron 2008, 64, 11304-11312.

[15] F. Fache, F. Valot, A. Milenkovic, M. Lemaire, Tetrahedron 1996, 52, 9777-9784.

Received: September 8, 2014 Published Online: October 15, 2014 